\title{
Estimated cumulative incidence of pandemic (H1N1) influenza among pregnant women during the first wave of the 2009 pandemic
}

\author{
Salaheddin M. Mahmud MD PhD, Marissa Becker MD, Yoav Keynan MD, Lawrence Elliott MD MSc, \\ Laura H. Thompson MSc, Keith Fowke PhD, Lisa Avery MD MSc, Paul Van Caeseele MD, \\ Sande Harlos MD MSc, James Blanchard MD PhD, Magdy Dawood PhD
}

Previously published at www.cmaj.ca

\section{ABSTRACT}

Background: Hospitalization and lab confirmed cases of H1N1 have been reported during the first wave of the 2009 pandemic but these are not accurate measures of influenza incidence in the population. We estimated the cumulative incidence of pandemic (H1N1) influenza among pregnant women in the province of Manitoba during the first wave of the 2009 pandemic.

Methods: Two panels of stored frozen serum specimens collected for routine prenatal screening were randomly selected for testing before (March 2009, $n=252$ ) and after (August 2009, $n=296$ ) the first wave of the pandemic. A standard hemagglutination inhibition assay was used to detect the presence of IgG antibodies against the pandemic (H1N1) 2009 virus. The cumulative incidence of pandemic (H1N1) influenza was calculated as the difference between the point prevalence rates in the first and second panels.

Results: Of the specimens collected in March, $7.1 \%$ were positive for the IgG antibodies (serum antibody titre $\geq 1: 40$ ). The corresponding prevalence was $15.7 \%$ among the specimens collected in August. The difference indicated a cumulative incidence of $8.6 \%$ (95\% confidence interval $[\mathrm{Cl}] 3.2 \%$ $13.7 \%)$. The rate differed geographically, the highest being in the northern regions $(20.8 \%, 95 \% \mathrm{Cl} 7.9 \%-31.8 \%)$, as compared with $4.0 \%(95 \% \mathrm{Cl} 0.0 \%-11.9 \%)$ in Winnipeg and $8.9 \%(95 \% \mathrm{Cl} 0.0 \%-18.8 \%)$ in the rest of the province.

Interpretation: We estimated that the cumulative incidence of pandemic (H1N1) influenza among pregnant women in Manitoba during the first wave of the 2009 pandemic was $8.6 \%$. It was $20.8 \%$ in the northern regions of the province.

$\mathrm{D}$ uring the first wave of the pandemic (H1N1) 2009, the province of Manitoba was more severely affected than almost any other Canadian province. Pregnant women in particular had higher rates of laboratoryconfirmed infection and of severe illness. ${ }^{2}$ However, the number of laboratory-confirmed cases is not an accurate measure of the incidence of influenza in the population. The number and geographic distribution of confirmed cases are influenced by differences in access to medical care, physicians' practices and other factors. ${ }^{3}$
We estimated the cumulative incidence of pandemic (H1N1) influenza among pregnant women in the province of Manitoba during the first wave of the 2009 pandemic. We did this by measuring the point seroprevalence in random samples of pregnant women presenting for routine prenatal screening before and after the first wave.

\section{Methods}

The Manitoba Maternal Serum Screening Program is a province-wide prenatal screening program offered free of charge to all pregnant women between 15 and 22 weeks' gestation. ${ }^{4}$ Participation rates in the program are high $(>70 \%) .{ }^{5,6}$ All specimens from the program are tested, and subsequently stored for one year, at the Cadham Provincial Laboratory.

We tested a random sample of 296 serum specimens collected from women presenting for prenatal screening at the end of the first wave (August 2009) using a hemagglutination inhibition assay to detect IgG antibodies against the pandemic strain of the virus (see Appendix 1, available at www.cmaj.ca /cgi/content/full/cmaj.100488/DC1). Because of concerns about potentially high levels of cross-reactivity with antibodies against pre-pandemic influenza strains,${ }^{8}$ we compared the seroprevalence estimates for the serum specimens collected after the first wave of the pandemic with estimates from a random sample of 252 specimens collected before the first wave (March 2009). Every woman's serum specimen had the same probability of being selected for testing, except for women residing in the less populous northern regions (North Eastman, NOR-MAN, Burntwood and Churchill regional health authorities); serum samples for all of these women were included to improve the precision of seroprevalence estimates in these regions. The study was conducted using anonymous, deidentified specimens. The study design was approved by the Health Research Ethics Board of the University of Manitoba.

From the Departments of Community Health Sciences (Mahmud, Becker, Elliott, Thompson, Fowke, Avery, Harlos, Blanchard) and Medical Microbiology (Becker, Keynan, Elliott, Fowke, Van Caeseele, Dawood), University of Manitoba, Winnipeg, Man.; and the Cadham Provincial Laboratory (Van Caeseele, Dawood), Winnipeg, Man.

CMAJ 2010. DOI:10.1503/cmaj.100488 
Assuming a seroprevalence of $20 \%$ following the first wave of the pandemic (H1N1) 2009, with $\alpha$ set at 0.05 , we calculated a sample size of 246 for the panel of sera specimens obtained after the first wave, to ensure a $95 \%$ confidence interval (CI) no wider than $10 \%$.

For each of the two panels of serum specimens, we calculated the point seroprevalence of pandemic (H1N1) influenza as the proportion of specimens with an antibody titre of 1:40 or greater in the hemagglutination inhibition assay. ${ }^{9-11}$ The cumulative incidence was then calculated as the difference between the point prevalence rates for the March and August panels. Because of oversampling from the northern regions of the province, each individual observation was weighted by the inverse of its sampling fraction. For each cumulative incidence estimate, we calculated a 95\% CI using biascorrected boot-strapped standard errors. $^{12}$

\section{Results}

The two panels of serum specimens were generally representative of the sampling frame and the population of all pregnant women in the province in terms of their age composition and geographic distribution (data not shown). The median age was 28 (range 16-40) years for the women whose samples were collected in March and 27 (range 1643) years for those whose samples were collected in August $(p=0.52)$.

Overall, $7.1 \%$ of the serum specimens collected in March and $15.7 \%$ of those collected in August were positive for antibodies against the pandemic (H1N1) virus (Table 1). From these rates, we calculated the cumulative incidence to be $8.6 \%$ (95\% CI 3.2\%-13.7\%). The cumulative incidence was higher among younger women (age 14-27 years; $17.2 \%, 95 \%$ CI $8.6 \%-25.4 \%)$ than among older women $(3.6 \%, 95 \% \mathrm{CI}$ $0.0 \%-10.6 \%)$. The use of other cutoff points for positivity (titres of $1: 20$ and $1: 80$ ) did not change the estimates appreciably.

In the geographic analysis, which was limited by small numbers, the

Burntwood and Churchill). highest cumulative incidence at the cut-off titre of 1:40 was observed among the women in the northern regions $(20.8 \%$, 95\% CI $7.9 \%-31.8 \%$ ), as compared with $4.0 \%$ (95\% CI

Table 1: Estimated cumulative incidence of pandemic (H1N1) influenza among pregnant women during the first wave of the 2009 pandemic, by age group

\begin{tabular}{|c|c|c|c|c|}
\hline \multirow{2}{*}{$\begin{array}{l}\text { Cut-off point for } \\
\text { positivity; age } \\
\text { group, yr }\end{array}$} & \multirow[b]{2}{*}{ No.* } & \multicolumn{2}{|c|}{ Point prevalence, $\%$} & \multirow[b]{2}{*}{$\begin{array}{c}\text { Cumulative incidence, } \uparrow \\
\%(95 \% \mathrm{Cl})\end{array}$} \\
\hline & & $\begin{array}{c}\text { In March } 2009 \\
n=252\end{array}$ & $\begin{array}{c}\text { In August } 2009 \\
n=296\end{array}$ & \\
\hline \multicolumn{5}{|l|}{ HIA titre $\geq 1: 20$} \\
\hline $14-27$ & 150 & 23.9 & 36.0 & $12.1(1.1-23.3)$ \\
\hline $28-44$ & 146 & 19.3 & 23.3 & $4.0(0.0-13.1)$ \\
\hline All & 296 & 21.4 & 27.3 & $5.9(0.0-12.6)$ \\
\hline \multicolumn{5}{|l|}{ HIA titre $\geq 1: 40$} \\
\hline $14-27$ & 150 & 6.8 & 24.0 & $17.2(8.6-25.4)$ \\
\hline $28-44$ & 146 & 7.4 & 11.0 & $3.6(0.0-10.6)$ \\
\hline All & 296 & 7.1 & 15.7 & $8.6(3.2-13.7)$ \\
\hline \multicolumn{5}{|l|}{ HIA titre $\geq 1: 80$} \\
\hline $14-27$ & 150 & 2.6 & 14.0 & $11.4(5.5-18.0)$ \\
\hline $28-44$ & 146 & 1.5 & 6.8 & $5.4(1.2-10.1)$ \\
\hline All & 296 & 2.0 & 10.0 & $8.0(4.4-12.2)$ \\
\hline
\end{tabular}

Note: $\mathrm{Cl}=$ confidence interval, $\mathrm{HIA}$ = hemagglutination inhibition assay.

*The number of specimens tested in August.

+Calculated as the difference between the point prevalence estimates in March and August 2009.

Table 2: Estimated cumulative incidence of pandemic (H1N1) influenza among pregnant women during the first wave of the 2009 pandemic, by region of residence

Point prevalence, \%

Cut-off point for In March 2009 In August 2009 Cumulative incidence, $\neq$ positivity; region* No.t $n=252 \quad n=296 \quad \%(95 \% \mathrm{Cl})$

\begin{tabular}{|lrrrr}
\hline HIA titre $\geq \mathbf{1 : 2 0}$ & & & & \\
\hline Winnipeg & 126 & 17.3 & 22.2 & $4.9(0.0-14.7)$ \\
\hline Northern Manitoba & 90 & 25.6 & 43.3 & $17.8(2.0-33.1)$ \\
\hline Elsewhere & 80 & 25.6 & 26.3 & $0.6(0.0-14.9)$ \\
\hline All & 296 & 21.4 & 27.3 & $5.9(0.0-12.6)$ \\
\hline HIA titre $\geq \mathbf{1 : 4 0}$ & & & & \\
\hline Winnipeg & 126 & 7.1 & 11.1 & $4.0(0.0-11.9)$ \\
\hline Northern Manitoba & 90 & 7.0 & 27.8 & $20.8(7.9-31.8)$ \\
\hline Elsewhere & 80 & 7.3 & 16.3 & $8.9(0.0-18.8)$ \\
\hline All & 296 & 7.1 & 15.7 & $8.6(3.2-13.7)$ \\
\hline HIA titre $\geq \mathbf{1 : 8 0}$ & & & & \\
\hline Winnipeg & 126 & 1.6 & 7.1 & $5.6(1.0-11.5)$ \\
\hline Northern Manitoba & 90 & 0.0 & 13.3 & $13.3(7.0-21.0)$ \\
\hline Elsewhere & 80 & 3.7 & 12.5 & $8.8(1.0-17.0)$ \\
\hline All & 296 & 2.0 & 10.0 & $8.0(4.4-12.2)$ \\
\hline
\end{tabular}

Note: $\mathrm{Cl}=$ confidence interval, $\mathrm{HIA}$ = hemagglutination inhibition assay.

*Northern Manitoba refers to four northern regional health authorities (North Eastman, NOR-MAN,

tThe number of specimens tested in August.

¥Calculated as the difference between the point prevalence estimates in March and August 2009. 
$0.0 \%-11.9 \%)$ in the Winnipeg region and $8.9 \%(95 \% \mathrm{CI}$ $0.0 \%-18.8 \%$ ) in the rest of the province (Table 2). At this cut-off titre, positivity levels for the specimens collected in March were similar across all regions (range 7.0\%-7.3\%). Despite the small numbers, similar patterns emerged when the data were stratified by both region and age group (data not shown).

\section{Interpretation}

Our results are consistent with the rates of laboratory-confirmed pandemic (H1N1) influenza and of hospital admissions and severe illness observed in the first wave of the 2009 pandemic, all of which were much higher in northern Manitoba. ${ }^{13}$ This geographic pattern was reversed during the second wave (October-December 2009), possibly because of higher levels of herd immunity after the first wave in the northern regions of the province.

The reasons for the higher cumulative incidence in the northern regions during the first wave are not clear. Aboriginal communities, with younger populations,${ }^{14}$ represent the majority of the population of northern Manitoba, which may explain some of the differences. Unfortunately, we could not reliably adjust our estimates for age-related differences because of the small numbers. It has been proposed that the uniformity of the patterns of pandemic (H1N1) influenza among Aboriginal communities across the globe, despite their genetic diversity, suggests a role for socio-economic and environmental factors, such as overcrowding, poor housing and limited access to health care services. ${ }^{15}$

\section{Limitations}

Our estimates may not be generalizable to the rest of the young adult population in Manitoba, because pregnant women may be at increased risk of pandemic (H1N1) influenza, if one assumes that pregnancy is a marker of increased contact with children. ${ }^{16}$ However, our results are comparable to those reported in a study from England that used a similar design to ours but was not restricted to pregnant women. ${ }^{17}$

The relatively small sample limited our ability to measure the cumulative incidence precisely, particularly in the geographic analysis. Also, pregnant women who did not undergo routine prenatal screening were not represented; however, the included women appeared to be representative of the population of all pregnant women. Women whose serum specimens were collected in August, after the first wave of the pandemic, were slightly younger than women whose specimens were in the March panel, which may have inflated our estimates.

The hemagglutination inhibition assay is not very specific.? However, we compared seroprevalence estimates before and after the first wave of the pandemic to minimize the resulting upward bias. Finally, the antibody titre corresponding to adequate protection against pandemic (H1N1) influenza is not known; we therefore used a range of cut-off points, all of which yielded consistent results.

\section{Conclusion}

Our study showed that the cumulative incidence of pandemic (H1N1) influenza during the first wave of the 2009 pandemic was $8.6 \%$ among pregnant women in Manitoba. The rate was $20.8 \%$ in the northern regions of the province.

This article has been peer reviewed.

Competing interests: None delcared.

Contributors: Salaheddin Mahmud, Marissa Becker, Lawrence Elliott, Lisa Avery, Paul Van Caeseele, Sande Harlos, James Blanchard and Magdy Dawood were involved in the study concept and design. Salaheddin Mahmud, Yoav Keynan, Keith Fowke, Paul Van Caeseele, James Blanchard and Magdy Dawood were involved in the acquisition of data. Salaheddin Mahmud, Marissa Becker, Yoav Keynan, Lawrence Elliott, Laura Thompson, Keith Fowke, Paul Van Caeseele and James Blanchard were involved in the analysis and interpretation of the data. Salaheddin Mahmud, Yoav Keynan, Keith Fowke and Magdy Dawood drafted the manuscript. All of the authors critically revised the manuscript for important intellectual content and approved the version submitted for publication.

Funding: This work was supported in part by a grant from the Public Health Agency of Canada. The agency did not play a role in the design and conduct of the study; the collection, management, analysis and interpretation of the data; or the preparation, review and approval of the manuscript.

Disclaimer: The interpretation and conclusions contained herein are those of the authors and do not necessarily represent those of the Government of Manitoba, the Manitoba Ministry of Health or the Public Health Agency of Canada.

\section{REFERENCES}

1. Kumar A, Zarychanski R, Pinto R, et al. Critically ill patients with 2009 influenza A(H1N1) infection in Canada. JAMA 2009;302:1872-9.

2. Oluyomi-Obi T, Avery L, Schneider C, et al. Perinatal and maternal outcomes in critically ill obstetrics patients with pandemic H1N1 influenza A. J Obstet Gynaecol Can 2010;32:443-7.

3. Garske T, Legrand J, Donnelly CA, et al. Assessing the severity of the novel influenza A/H1N1 pandemic. BMJ 2009;339:b2840.

4. Chodirker BN, Evans JA. Maternal serum AFP screening rograms: the Manitoba experience. In: Current practice of prenatal diagnosis in Canada. Research Studies. Volume 13. Ottawa (ON): Royal Commission on New Reproductive Technologies; 1993. p. 535-610.

5. Baschat AA, Harman CR, Farid G, et al. Very low second-trimester maternal serum alpha-fetoprotein: association with high birth weight. Obstet Gynecol 2002;99:531-6.

6. Public Health Agency of Canada. Canadian Congenital Anomalies Surveillance Network. Directory of surveillance systems. Ottawa (ON): The Agency; 2010. Available: www.phac-aspc.gc.ca/ccasn-rcsac/dss/man-eng.php (accessed 2010 Jan. 17).

7. Webster R, Cox N, Stohr K. WHO manual on animal influenza diagnosis and surveillance. Geneva (Switzerland): World Health Organization; 2002.

8. Katz, Hancock, Veguilla, Zhong, et al. Serum cross-reactive antibody response to a novel influenza A (H1N1) virus after vaccination with seasonal influenza vaccine. MMWR Morb Mortal Wkly Rep 2009;58:521-4.

9. Sandbulte MR, Jimenez GS, Boon AC, et al. Cross-reactive neuraminidase antibodies afford partial protection against $\mathrm{H} 5 \mathrm{~N} 1$ in mice and are present in unexposed humans. PLoS Med 2007;4:e59.

10. de Jong JC, Palache AM, Beyer WE, et al. Haemagglutination-inhibiting antibody to influenza virus. Dev Biol (Basel) 2003;115:63-73.

11. Potter C, Oxford J. Determinants of immunity to influenza infection in man. $\mathrm{Br}$ Med Bull 1979;35:69-75.

12. Efron B, Tibshirani RJ. An introduction to the bootstrap. London (UK): Chapman \& Hall/CRC; 1994.

13. Health M. General information on lab-confirmed cases of pandemic H1N1 influenza. Winnipeg (MB): Manitoba Health; 2010. Available: www.gov.mb.ca /health/publichealth/sri/stats1.html (accessed 2010 July 10).

14. Women in Canada. Ottawa (ON): Statistics Canada; 2006. Cat. no. 89503 XIE. Available: www.statcan.gc.ca/pub/89-503-x/89-503-x2005001-eng.pdf (accessed 2009 Jan. 11).

15. La Ruche G, Tarantola A, Barboza P, et al. The 2009 pandemic H1N1 influenza and indigenous populations of the Americas and the Pacific. Euro Surveill 2009;14 (42).

16. Fiore AE, Neuzil KM. 2009 influenza A(H1N1) monovalent vaccines for children JAMA 2010;303:73-4

17. Miller E, Hoschler K, Hardelid P, et al. Incidence of 2009 pandemic influenza A H1N1 infection in England: a cross-sectional serological study. Lancet 2010;375:1100-8.

Correspondence to: Dr. Salaheddin Mahmud, Department of Community Health Sciences, University of Manitoba, Rm. S113, Medical Services Building, 750 Bannatyne Ave., Winnipeg $M B$ R3E0W3; salah.mahmud@gmail.com 